\title{
Does spinal chloroprocaine pharmacokinetic profile actually translate into a clinical advantage in terms of clinical outcomes when compared to low-dose spinal bupivacaine? A systematic review and meta-analysis
}

\author{
Andrea Saporito $^{\mathrm{a}}$, Marcello Ceppi ${ }^{\mathrm{b}}$, Andreas Perren ${ }^{\mathrm{c}}$, Davide La Regina ${ }^{\mathrm{d}}$, Stefano Cafarotti ${ }^{\mathrm{d}}$, \\ Alain Borgeat $^{\mathrm{e}, *}$, José Aguirre ${ }^{\mathrm{e}}$, Marc Van De Velde ${ }^{\mathrm{f}}$, An Teunkens ${ }^{\mathrm{f}}$ \\ ${ }^{a}$ Anesthesia Department, Bellinzona Regional Hospital, (Switzerland)

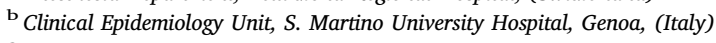 \\ ${ }^{\mathrm{c}}$ Intensive Care Unit, Bellinzona Regional Hospital, Switzerland \\ ${ }^{\mathrm{d}}$ Surgery Department, Bellinzona Regional Hospital, Switzerland \\ e Department of Anesthesiology, Balgrist University Hospital, Zurich, (Switzerland) \\ ${ }^{\mathrm{f}}$ Department of Anesthesiology, University Hospital of the KU, Leuven, Belgium
}

\section{A R T I C L E I N F O}

\section{Keywords:}

Spinal anesthesia

Chloroprocaine

Ambulatory surgery

Fast-track surgery

\begin{abstract}
A B S T R A C T
Study objective: Spinal anesthesia is well suited for day-care surgery, however a persisting motor block after surgery can delay discharge. Among the new drugs available, chloroprocaine has been associated with a short onset time, and motor block duration and a quicker discharge. However, it is not clear if those outcomes are clinically significantly superior compared to those associated with the use of low-dose hyperbaric bupivacaine. Design: Aim of the study was to determine if spinal 2-chloroprocaine was superior to low-dose spinal bupivacaine regarding the following outcomes: onset time, block duration, time to ambulation and time to discharge. Patients/interventions: We performed a systematic literature search of the last 30 years using PubMed Embase and the Cochrane Controlled Trials Register. We included only blinded, prospective trials comparing chloroprocaine with a low dose of bupivacaine for spinal anesthesia. Low dose bupivacaine was defined as a dose of $10 \mathrm{mg}$ or less. Outcomes of interest were time to motor block regression (primary outcome), time to ambulation and time to discharge (secondary outcomes), as indirect indicators of a complete recovery after spinal anesthesia.

Main results: Compared to a low dose bupivacaine, spinal 2-chloroprocaine was associated with significantly faster motor and sensory block regression ( $\mathrm{pMD}=-57 \mathrm{~min}-140.3 \mathrm{~min} ; P=0.015$ and $<0.001$ respectively), a significantly shorter time to ambulation and an earlier discharge (pMD $=-84.6 \mathrm{~min} ; P<0.001$ and $\mathrm{pMD}=-88.6 \mathrm{~min}$ and $<0.001$ respectively). Onset time did not differ between the two drugs (pMD $=-1.1 \mathrm{~min} ; P=0.118)$.

Conclusions: Spinal 2-chloroprocaine has a shorter motor block duration, a significantly quicker time to ambulation and time to discharge compared to low dose hyperbaric bupivacaine and may be advantageous when spinal anesthesia is performed for day case surgery.
\end{abstract}

\section{Introduction}

When performed under spinal anesthesia, procedures characterized by a short duration and a high turnover ideally demand the use of local anesthetics, the pharmacokinetics of which profile allows for a quick recovery and a fast discharge [1].

Lidocaine has an attractive pharmacokinetic profile, with a rapid onset and fast recovery of both sensory and motor block (130-170 min)
[2]; however, concerns regarding the risk of transient neurological symptoms (TNS) has limited its widespread clinical use [3-5].

Since its introduction in the 1960s, bupivacaine became the most widespread alternative to lidocaine, showing a lower incidence of TNS; however, its duration of action (240-380 min) might be incompatible with an early rehabilitation and a quick discharge [6]. Moreover, it might cause unpredictable levels of anesthesia, which are dose dependent and may lead to complications, such as hemodynamic instability

\footnotetext{
* Corresponding author at: Department of Anesthesiology, Balgrist University Hospital, Forchstrasse 340, 8008 Zurich, Switzerland.

E-mail address: alain.borgeat@balgrist.ch (A. Borgeat).
} 
[7-9].

The use of smaller doses of bupivacaine was introduced to avoid these issues; however, low-dose spinal bupivacaine has still been associated to prolonged motor blocks and may lead to an inadequate block height for some surgical procedure [7]. On the other side, BenDavid et al. showed that $7.5 \mathrm{mg}$ of $0.5 \%$ hyperbaric bupivacaine can provide adequate spinal anesthesia for ambulatory surgery, when compared with both smaller and larger doses of plain bupivacaine [10].

Recently, 2-chloroprocaine has regained popularity due to its favorable pharmacokinetic properties. It was withdrawn from the market in the 1980s due to concerns about neurotoxicity [11-13] reintroduced in 2004 into clinical practice in a new formulation without preservatives. 2-chloroprocaine shows both a very fast onset (5-10 min) and a quick recovery time $(70-150 \mathrm{~min})[14,15]$. In doses ranging between 30 and $60 \mathrm{mg}$, spinal block profile is similar to that of lidocaine, with a significantly lower incidence of TNS $[16,17]$.

The clinical characteristics of spinal 2-chloroprocaine are similar to lidocaine $[16,17]$. However, the impact of the time to motor block regression on patient discharge remain unclear in the literature. Mepivacaine, another short-medium duration local anesthetic, is not registered in many countries for intrathecal use, has a high incidence of TNS and has been compared to lidocaine [18] but not with 2-chloroprocaine for spinal anesthesia.

Bupivacaine using hyperbaric formulation and low doses ( $\leq 10 \mathrm{mg}$ ) is the main clinically used comparator to 2-chloroprocaine in current ambulatory literature due to its wide spread use and low TNS risk. Therefore, we performed a meta-analysis of blinded, randomised studies comparing low-dose $(\leq 10 \mathrm{mg}$ ) hyperbaric bupivacaine to 2chloroprocaine for spinal anesthesia. Our primary outcome was motor block duration and our hypothesis was that due to its pharmacological characteristics, 2-chloroprocaine would show a significantly shorter motor block regression time.

Secondary outcomes were the time to ambulation, to discharge, sensory onset and offset block time and complication rate.

\section{Materials and methods}

A systematic review was designed in accordance with the Preferred Reporting Items for Systematic Reviews and Meta-Analyses (PRISMA) Statement [19] and the Cochrane Handbook for Systematic Reviews of Interventions [20].

All prospective randomised, controlled trials dealing with ambulatory or inpatient spinal anesthesia were identified using a validated methodology, as described by Dickersin and colleagues [21] performing a computerized search of the electronic databases PubMed, EMBASE and the Cochrane Controlled Trials Register for papers published between May 1987 and May 2017. Only studies in the English language were considered. Maximally expanded search terms with Boolean operators (OR, AND) for the terms "chloroprocaine", "bupivacaine", "spinal anesthesia", "spinal anesthesia", "low dose", "motor block", "sensory block", "discharge", "ambulation", "offset time" and "onset time" were used. Results were further limited by combining with "time to motor block offset" OR "time to motor block remission" OR "time to motor block regression" OR "time to ambulation", using the Boolean operator AND.

Moreover, the clinical trials database, ClincalTrials.gov, was searched. An additional manual search for theme-related review articles and other relevant material was performed to identify other studies with a 'snowballing' technique. The references from all studies were screened for additional literature. Duplicates were eliminated.

We included only double-blind, randomised, controlled trials on adults after written informed consent and ethical committee approval, comparing chloroprocaine with a small dose of bupivacaine for spinal anesthesia. We considered as 'low dose' bupivacaine a dose of $10 \mathrm{mg}$ or less, as doses between 5 and $10 \mathrm{mg}$ are considered to be low-dose for lower extremity and abdominal surgery [22].
Outcomes of interest were time to motor block regression (primary outcome), time to ambulation and time to discharge (secondary outcomes), as indirect indicators of a complete recovery after spinal anesthesia. Onset time (secondary outcome) was considered an indirect measure of efficacy. Transient neurologic symptoms (TNS) and postoperative urinary retention (POUR) requiring bladder catheterization were assessed as complications. No restrictions were applied to the technique adopted and the materials used.

Two reviewers independently assessed each title for inclusion (A.S., J.A.), and relevant abstracts were independently evaluated. If doubt existed regarding relevance, the full text article was assessed.

The methodologic quality of all included studies was scored independently by 2 of the authors (A.S. and J.A.) according to a scoring system based on the system developed by Jadad et al. [23] and the modification described in two recent reviews [24,25]. Each study could receive a maximum score of 13 . The method of randomization and blinding techniques were considered the most important and could draw a maximum score of 3 points each. All other items could draw a score of 1 point. Studies with scores of 5 or less were considered poor quality and were excluded from further analysis. Those with scores of 6 to 10 were found moderate quality studies and those with scores of 11 or higher were considered good quality studies. Any conflicts in the scoring system were resolved by a third independent reviewer (A.P.).

Data from each of the included studies were successively extracted into an electronic database according to the following parameters: time to motor block regression, time to sensory block regression, time to ambulation, time to discharge.

When data were expressed as medians and interquartile ranges, the first Author of the correspondent study was contacted and asked to provide original rough data in order to calculate means and standard deviations (SD).

As effect estimate, we computed for each study the difference (MD) between the mean times of motor block regression, sensory block regression, onset time, time to ambulation and time to discharge recorded in patients treated with 2-chloroprocaine and bupivacaine, respectively.

To estimate the overall measure of the effect, i.e. the pooled MD (pMD), we computed the weighted mean of the MDs using as weight the inverse of the MD variance, which was estimated as the sum of the deviances of the mean times of each drug divided by the degrees of freedom.

The pooled estimate of the MD was computed using the random effects model following the method of DerSimonian and Laird [26]. This model allowed to estimate the amount of the variability between studies and accordingly provided suitable estimates of the standard errors of the parameters.

The Higgins' I ${ }^{2}$ index [26] was calculated to assess the percentage of total cross-study variation due to heterogeneity rather than chance. A forest plot was generated to display results.

We carried out the sensitivity analysis by iteratively recalculating the pooled MD estimate after exclusion of each study at a time. This analysis inspects whether the pooled estimate is strongly dependent on one of the studies collected i.e. if the selection criteria influenced the result of the meta-analysis. The occurrence of publication bias was assessed by visual inspection of the funnel plot and by performing the Egger test to check for small study effect.

STATA software was used for all statistical analyses and the generation of forest plot (StataCorp. (2015) Stata Statistical Software: Release 14. College Station, TX: StataCorp LP).

\section{Results}

A total of 33 articles were identified using previously described search terms combinations. After analyzing all the articles full text, only four trials matched all the inclusion criteria. From relevant citations and references analysis, no additional studies were identified. Fig. 1 


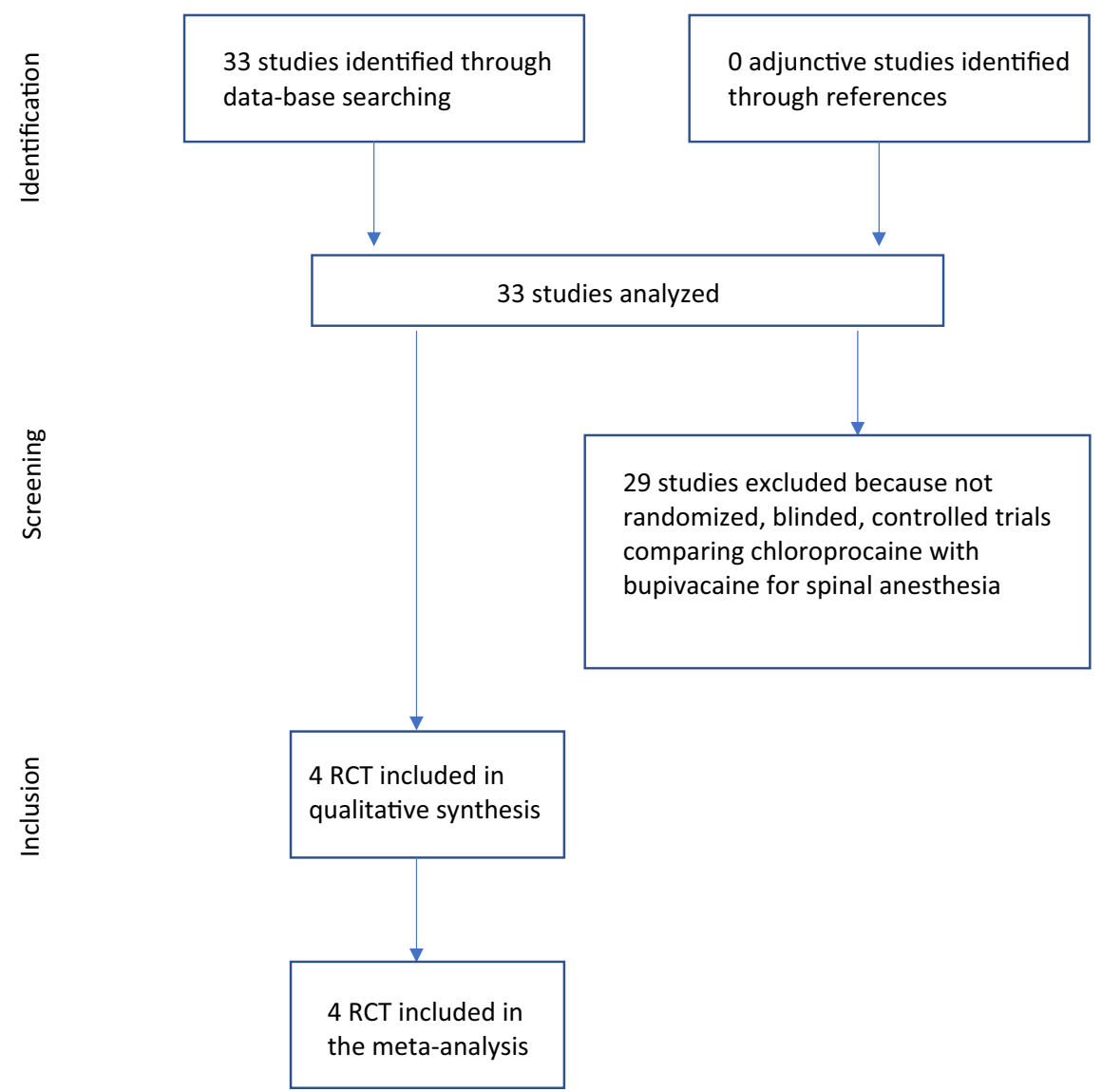

Fig. 1. PRISMA flowchart illustrating the studies selection process.

illustrates the selection process through a PRISMA flowchart.

The four studies included are reported in Tables 1 \& 2 [27-30]. These four studies together feature a total of 109 patients treated with $40 \mathrm{mg}$ of $2 \% 2$-chloroprocaine and 114 patients treated with hyperbaric bupivacaine $0.5 \%$. Thus data from a total of 223 patients were pooled and analyzed in this meta-analysis.

All the four studies included were considered of good quality according to the modified Jadad criteria with scores $>11$.

Primary outcome (motor block regression time) was present in all the studies included. A subgroup analysis was performed with regard to secondary outcomes on the studies where relative data were present. Time to discharge, sensory block regression and ambulation time were reported in all but one studies, while onset time featuring in only two studies. (Fig. 2).

All outcomes analyzed except onset time, significantly favored 2chloroprocaine (Fig. 2): when performed with 2-chloroprocaine, spinal anesthesia had similar onset time as if performed with bupivacaine, but was associated with a significantly quicker motor and sensory block regression, which translated into shorter time to ambulation and to discharge.

One study described one case of TNS in each group $(7.5 \mathrm{mg}$ hyperbaric bupivacaine $0.75 \%$ and $40 \mathrm{mg}$ 2-Chloroprocaine $2 \%$ ) and no study reported the need of bladder catheterization due to POUR [28]. Excluding time to discharge, heterogeneity is quite large in all endpoints. However, despite that the differences in the times of the two drugs are quite variable, a reduction in favor of 2-chloroprocaine is observed in all studies, making the results of the meta-analysis reliable. In addition, the random effect model, when heterogeneity is high, estimates more accurate confidence intervals of pooled MD than fixed effect model.

Sensitivity analysis reveals that in all endpoints but onset time the difference between mean times remains significant in favor of 2-

Table 1

Studies included in the meta-analysis. Means and standard deviations (SD) are reported for all the assessed outcomes (Bupi: bupivacaine 5\%, 2-CP: 2Chloroprocaine).

\begin{tabular}{|c|c|c|c|c|c|c|c|c|c|c|c|c|}
\hline & \multicolumn{2}{|c|}{ Patients } & \multicolumn{2}{|c|}{$\begin{array}{l}\text { Motor Block } \\
\text { Regression }\end{array}$} & \multicolumn{2}{|l|}{ Onset time } & \multicolumn{2}{|c|}{$\begin{array}{l}\text { Sensor block } \\
\text { regression }\end{array}$} & \multicolumn{2}{|l|}{$\begin{array}{l}\text { Time to } \\
\text { ambulation }\end{array}$} & \multicolumn{2}{|l|}{$\begin{array}{l}\text { Time to } \\
\text { discharge }\end{array}$} \\
\hline & 2-CP & Bupi & 2-CP & Bupi & 2-CP & Bupi & 2-CP & Bupi & $2-\mathrm{CP}$ & Bupi & 2-CP & Bupi \\
\hline & & & mean $(s d)$ & mean $(s d)$ & mean $(s d)$ & mean $(s d)$ & mean $(s d)$ & mean $(s d)$ & mean $(s d)$ & mean $(s d)$ & mean $(s d)$ & mean (sd) \\
\hline Yoos et al. [30] & 8 & 8 & $59(16)$ & $80(48)$ & $10(0)$ & $12(5)$ & $113(14)$ & $191(30)$ & $113(14)$ & $191(30)$ & $113(14)$ & $191(32)$ \\
\hline Lacasse et al. [28] & 53 & 53 & $76(25)$ & 119 (93) & $6(4)$ & $6(3)$ & $146(38)$ & $329(82)$ & $225(56)$ & $265(65)$ & 277 (87) & 353 (99) \\
\hline Maes et al. [27] & 18 & 19 & $77(20)$ & $89(28)$ & - & - & - & - & - & - & - & - \\
\hline Teunkens et al. [29] & 30 & 34 & $90(25)$ & $180(78)$ & - & - & $\begin{array}{l}144 \\
(33.6)\end{array}$ & $\begin{array}{l}306 \\
(76.8)\end{array}$ & $\begin{array}{l}204 \\
(46.2)\end{array}$ & $\begin{array}{r}282 \\
(77.4)\end{array}$ & $\begin{array}{l}276 \\
(79.2)\end{array}$ & $\begin{array}{l}342 \\
(82.2)\end{array}$ \\
\hline
\end{tabular}


Table 2

Details of studies included in the meta-analysis.

\begin{tabular}{|c|c|c|c|c|c|}
\hline Studies & $\begin{array}{l}\text { Sample } \\
\text { size } \\
\text { 2-CP vs. B }\end{array}$ & Setting & Sample size justification & Primary outcome & $\begin{array}{l}\text { Jadad } \\
\text { score }\end{array}$ \\
\hline Yoos et al. [30] & 8 vs. 8 & $\begin{array}{l}\text { Randomised, double blind, } \\
\text { crossover, volunteer study. }\end{array}$ & $\begin{array}{l}\text { Using a difference of } 15 \mathrm{~min} \text { in time to complete sensory resolution and } \\
\text { a standard deviation of } 10 \mathrm{~min}, 8 \text { patients per group were calculated. }\end{array}$ & $\begin{array}{l}\text { Complete sensory } \\
\text { resolution }\end{array}$ & 11 \\
\hline $\begin{array}{l}\text { Lacasse et al. } \\
\qquad[28]\end{array}$ & 53 vs. 53 & $\begin{array}{l}\text { Randomised, double blind } \\
\text { study. }\end{array}$ & $\begin{array}{l}\text { To obtain a } 60 \text {-min reduction in the eligibility for discharge a minimum } \\
\text { of } 53 \text { patients per group was required. }\end{array}$ & Time until discharge & 12 \\
\hline Maes et al. [27] & 18 vs. 19 & $\begin{array}{l}\text { Randomised, single blind, } \\
\text { controlled study }\end{array}$ & $\begin{array}{l}\text { A sample size of } 18 \text { patients per group was required to detect a } 15 \text { min } \\
\text { difference in regression of motor blockade. }\end{array}$ & $\begin{array}{l}\text { Complete regression of } \\
\text { motor blockade }\end{array}$ & 11 \\
\hline $\begin{array}{l}\text { Teunkens et al. } \\
\text { [29] }\end{array}$ & & $\begin{array}{l}\text { Prospective, double blind, } \\
\text { randomised controlled study }\end{array}$ & $\begin{array}{l}\text { Sample size to detect a difference in complete recovery of sensory block } \\
\text { between the groups and was based on ambulation time that were } \\
\text { obtained from the literature for the different local anesthetics. Using a } \\
\text { conversion formula, a lognormal distribution for the time until block } \\
\text { recovery was assumed for each group. }\end{array}$ & $\begin{array}{l}\text { Time to complete } \\
\text { recovery of sensory } \\
\text { block }\end{array}$ & 13 \\
\hline
\end{tabular}

2-CP: 2-chloroprocaine, B: bupivacaine.

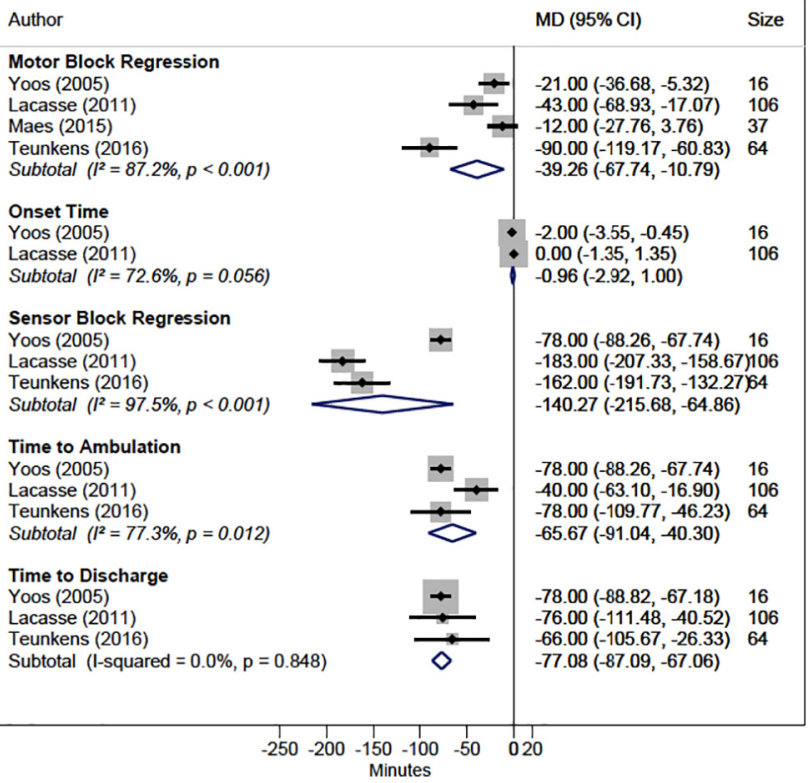

Fig. 2. Forest plot of the studies included in the meta-analysis; data are expressed in minutes; studies left of the line are significantly in favor of lower times related to chloroprocaine use (MD: mean times difference; pMD: pooled mean times difference; CI: confidence intervals).

\section{chloroprocaine.}

The funnel plot applied to motor block regression time (Fig. 3), the primary outcome of the studies, shows that the studies were randomly spread around the pooled estimate; moreover, the Eggert test did not suggest the occurrence of the small study effect $(P=0.08)$.

\section{Discussion}

Compared to low-dose bupivacaine, the application of 2-chloroprocaine for spinal anesthesia significantly reduces both motor and sensory block regression time, leading to a significant time reduction to ambulation and consequently time to discharge. Spinal anesthesia onset-time does not differ significantly between the two drugs. Incidence of TNS is similar [28] and no report of postoperative urinary retention (POUR) requiring bladder catheterization was reported in either groups.

These results seem to favor the use of 2-chloroprocaine for spinal anesthesia in ambulatory setting, as this requires reliable blocks, with a quick onset time and a short persistent motor block, leading to a quick recovery and thus a predictable discharge times [31].

Spinal anesthesia performed under the above characteristics is a technique competing with general anesthesia for ambulatory surgery, as shown by a meta-analysis [32]. Liu et al. could show that regional anesthesia leads to decreased post anesthesia care unit use, nausea, and postoperative pain. However, neither central neuraxial block nor peripheral nerve block were associated with reduced ambulatory surgery unit time. Moreover, spinal 2-chloroprocaine has been shown to be favorable for many ambulatory procedures, compared with other shortacting local anesthetics like lidocaine and articaine [33-36]. In these studies, 2-chloroprocaine showed significantly shorter recovery times leading to shorter discharge times. However, despite low-dose bupivacaine has been used in the outpatient setting leading to a reasonably short PACU discharge time of 65-98 min, the risk of primary block failure of 4\% seemed excessively high [37]. Furthermore, unilateral spinal anesthesia with 5-7.5 mg of bupivacaine was shown to be inconstant in providing reliable sensory and motor blocks for gynecologic and abdominal surgery [6]. As in some of the included studies, other authors have reported a wide variation in the recovery profiles when bupivacaine was used for spinal anesthesia (with resulting motor block sometimes exceeding $300 \mathrm{~min}$ ), making bupivacaine not really suitable for outpatient anesthesia [6].

The dose of 2-chloroprocaine in the included studies varied from 40 to $50 \mathrm{mg}$. Previous dose-finding studies showed that $30 \mathrm{mg}$ was associated with an insufficient duration of analgesia for surgery procedures over $60 \mathrm{~min}$ or more, whereas time to complete block resolution was significantly prolonged when a dose of $50 \mathrm{mg}$ is used. A dose of $40 \mathrm{mg}$ thus seems to be a good compromise [38-40]. These results led to the following recommendations by Goldblum and Atchabahian: $30 \mathrm{mg}$ of plain 2-chloroprocaine for surgery up to $40-60 \mathrm{~min}, 40-45 \mathrm{mg}$ for 45-70 min, and $60 \mathrm{mg}$ for 60-90 min duration respectively [14]. In fact, a dose of $40 \mathrm{mg}$ of 2-chloroprocaine was shown to provide a reliable anesthetic block duration of $60 \mathrm{~min}$, with a time to readiness for discharge of $120 \mathrm{~min}$, with a very low variability [16]. These data are in accordance with the results of our meta-analysis (see Table 1).

Spinal anesthesia interferes with the micturition reflex and bladder function is impaired until the block regresses below the third sacral segment [41]. Thus, bupivacaine or high-dose lidocaine may lead to urinary retention. Risk factors, including male sex, age, history of previous urologic dysfunction, pelvic and prolonged surgery, further increase the risk of POUR [42]. Choi et al. and Mulroy et al. independently suggested in two reviews concrete strategies on how to manage urinary retention [43,44]. Unilateral low-dose spinal anesthesia ( $6 \mathrm{mg}$ bupivacaine) did not decrease the incidence of urinary retention in high-risk patients [45]. Patients with a low POUR risk apparently have a low incidence of urinary retention after spinal anesthesia with a short-acting local anesthetic compared to general anesthesia $[33,46,47]$. However, the use of a short-acting local anesthetic does not exclude micturition. Breebaart et al. compared spinal lidocaine to spinal 2-chloroprocaine for outpatient surgery [35]. The two groups 


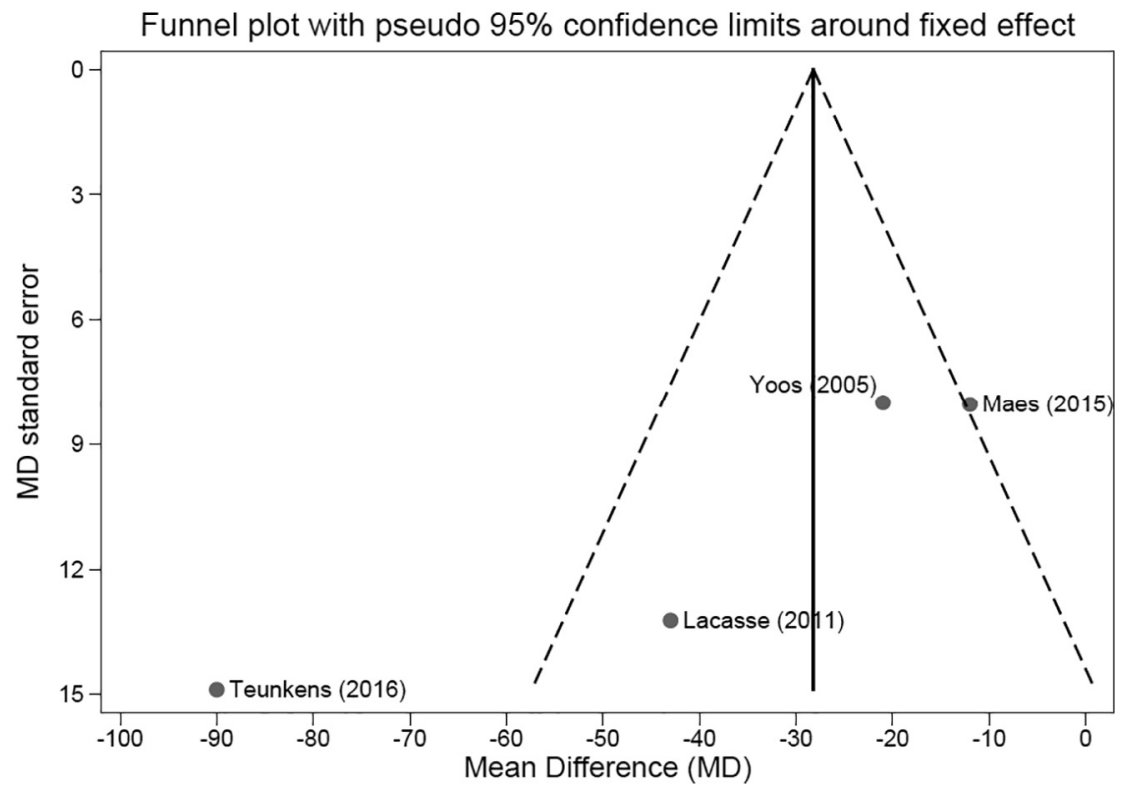

Fig. 3. Funnel plot applied to motor block regression time outcome shows that the studies were randomly spread around the pooled estimate.

received either or not an intravenous preload of $500 \mathrm{~mL}$ crystalloid. The preload increased the bladder volume at PACU admission but did not hasten the time to first micturition or discharge. These were not influenced by the type of local anesthetic. However, more micturition problems were encountered in the lidocaine groups, with five bladder catheterizations due to a sensory block above $\mathrm{S} 2$ with a bladder volume of $>500 \mathrm{ml}$. No one case of catheterization in the 2-chloroprocaine groups was reported. This issue is of a practical importance in the outpatient setting, as in many centers spontaneous voiding is a mandatory discharge criterion $[44,48,49]$. There are no reports of POUR associated to spinal 2-chloroprocaine, which is in accordance with our findings and represents a further potential advantage of this drug in the ambulatory setting $[33,35]$.

In conclusion, spinal 2-chloroprocaine offers a shorter motor block duration leading to a significantly quicker time to ambulation and time to discharge compared to low dose bupivacaine. According to the few available data, 2-chloroprocaine can be recommended when spinal anesthesia is performed for short cases performed in an ambulatory or fast-track setting. However, the impact of these results is limited by the small number of included studies, and further studies will be needed to confirm them.

\section{Declaration of interest}

None.

\section{Disclosure of funding}

No benefits in any form have been received or will be received from a commercial party related directly or indirectly to the subject of this article.

However, the authors AS, AB, JA and MvdV have participated in symposia sponsored by Sintetica, the company which markets chloroprocaine.

\section{Acknowledgements}

AS and AT made substantial contributions to the conception and design of the work and revising the work critically for important intellectual content and final approval of the version to be published and is in agreement to be accountable for all aspects of the work in ensuring that questions related to the accuracy or integrity of any part of the work are appropriately investigated and resolved.

$\mathrm{AB}$ and $\mathrm{MC}$ made substantial contributions to the conception and design of the work, the analysis, and interpretation of data for the work and drafting the work for important intellectual content and final approval of the version to be published and is in agreement to be accountable for all aspects of the work in ensuring that questions related to the accuracy or integrity of any part of the work are appropriately investigated and resolved.

JA made substantial contributions to the conception and design of the work, the acquisition, analysis (JA together with AS assessment of literature and its quality), and interpretation of data for the work and revising the work critically for important intellectual content and final approval of the version to be published and is in agreement to be accountable for all aspects of the work in ensuring that questions related to the accuracy or integrity of any part of the work are appropriately investigated and resolved.

AP and DLR made substantial contributions to the conception and design of the work, the statistical analysis of data and their interpretation for the present work. They revised work critically for important intellectual content and gave final approval of the version to be published and are in agreement to be accountable for all aspects of the work in ensuring that questions related to the accuracy or integrity of any part of the work are appropriately investigated and resolved.

AS, MvdV and AT made substantial contributions to the conception and design of the work and revising the work critically for important intellectual content and final approval of the version to be published and are in agreement to be accountable for all aspects of the work in ensuring that questions related to the accuracy or integrity of any part of the work are appropriately investigated and resolved.

Thank you to Alejandro Pellegrino (A.P.) for his help with the literature search, with the study quality assessment, his contribution to the statistical analysis and for the critical review of the manuscript.

\section{References}

[1] Korhonen AM. Use of spinal anaesthesia in day surgery. Curr Opin Anaesthesiol 2006;19:612-6.

[2] Liam BL, Yim CF, Chong JL. Dose response study of lidocaine 1\% for spinal anaesthesia for lower limb and perineal surgery. Can J Anaesth 1998;45:645-50.

[3] Zaric D, Pace NL. Transient neurologic symptoms (TNS) following spinal anaesthesia with lidocaine versus other local anaesthetics. Cochrane Database Syst Rev 2009;2. 
[4] Schneider M, Ettlin T, Kaufmann M, Schumacher P, Urwyler A, Hampl K, et al. Transient neurologic toxicity after hyperbaric subarachnoid anesthesia with 5\% lidocaine. Anesth Analg 1993;76:1154-7.

[5] Freedman JM, Li DK, Drasner K, Jaskela MC, Larsen B, Wi S. Transient neurologic symptoms after spinal anesthesia: an epidemiologic study of 1,863 patients. Anesthesiology 1998;89:633-41.

[6] Nair GS, Abrishami A, Lermitte J, Chung F. Systematic review of spinal anaesthesia using bupivacaine for ambulatory knee arthroscopy. Br J Anaesth 2009;102:307-15.

[7] Gupta A, Axelsson K, Thorn SE, Matthiessen P, Larsson LG, Holmstrom B, et al. Lowdose bupivacaine plus fentanyl for spinal anesthesia during ambulatory inguinal herniorrhaphy: a comparison between $6 \mathrm{mg}$ and $7.5 \mathrm{mg}$ of bupivacaine. Acta Anaesthesiol Scand 2003;47:13-9.

[8] Camponovo C, Wulf H, Ghisi D, Fanelli A, Riva T, Cristina D, et al. Intrathecal 1\% 2chloroprocaine vs. $0.5 \%$ bupivacaine in ambulatory surgery: a prospective, observer-blinded, randomised, controlled trial. Acta Anaesthesiol Scand 2014;58:560-6.

[9] Yoos JR, Kopacz DJ. Spinal 2-chloroprocaine: a comparison with small-dose bupivacaine in volunteers. Anesth Analg 2005;100:566-72.

[10] Ben-David B, Levin H, Solomon E, Admoni H, Vaida S. Spinal bupivacaine in ambulatory surgery: the effect of saline dilution. Anesth Analg 1996;83:716-20.

[11] Reisner LS, Hochman BN, Plumer MH. Persistent neurologic deficit and adhesive arachnoiditis following intrathecal 2-chloroprocaine injection. Anesth Analg 1980;59:452-4.

[12] Ravindran RS, Bond VK, Tasch MD, Gupta CD, Luerssen TG. Prolonged neural blockade following regional analgesia with 2-chloroprocaine. Anesth Analg 1980;59:447-51.

[13] Hampl K, Steinfeldt T, Wulf H. Spinal anesthesia revisited: toxicity of new and old drugs and compounds. Curr Opin Anaesthesiol 2014;27:549-55.

[14] Goldblum E, Atchabahian A. The use of 2-chloroprocaine for spinal anaesthesia. Acta Anaesthesiol Scand 2013;57:545-52.

[15] Pollock JE. Intrathecal chloroprocaine-not yet "safe" by US FDA parameters. Int Anesthesiol Clin 2012;50:93-100.

[16] Kouri ME, Kopacz DJ. Spinal 2-chloroprocaine: a comparison with lidocaine in volunteers. Anesth Analg 2004;98:75-80.

[17] Smith KN, Kopacz DJ, McDonald SB. Spinal 2-chloroprocaine: a dose-ranging study and the effect of added epinephrine. Anesth Analg 2004;98:81-8.

[18] Pawlowski J, Orr K, Kim KM, Pappas AL, Sukhani R, Jellish WS. Anesthetic and recovery profiles of lidocaine versus mepivacaine for spinal anesthesia in patients undergoing outpatient orthopedic arthroscopic procedures. J Clin Anesth 2012;24:109-15.

[19] Liberati A, Altman DG, Tetzlaff J, Mulrow C, Gotzsche PC, Ioannidis JP, et al. The PRISMA statement for reporting systematic reviews and meta-analyses of studies that evaluate health care interventions: explanation and elaboration. J Clin Epidemiol 2009;62:e1-34.

[20] Higgins JPT, Green S. Cochrane Handbook for Systematic Reviews of Interventions Version 5.1.0 (Updated March 2011). 2011.

[21] Klein SM, Pietrobon R, Nielsen KC, Warner DS, Greengrass RA, Steele SM. Peripheral nerve blockade with long-acting local anesthetics: a survey of the society for ambulatory anesthesia. Anesth Analg 2002;94:71-6.

[22] Buttner B, Mansur A, Bauer M, Hinz J, Bergmann I. Unilateral spinal anesthesia. Literature review and recommendations. Anaesthesist 2016;65:847-65.

[23] Jadad AR, Moore RA, Carroll D, Jenkinson C, Reynolds DJ, Gavaghan DJ, et al. Assessing the quality of reports of randomized clinical trials: is blinding necessary? Control Clin Trials 1996:17:1-12.

[24] Abrahams MS, Aziz MF, Fu RF, Horn JL. Ultrasound guidance compared with electrical neurostimulation for peripheral nerve block: a systematic review and meta-analysis of randomized controlled trials. Br J Anaesth 2009;102:408-17.

[25] Bingham AE, Fu R, Horn JL, Abrahams MS. Continuous peripheral nerve block compared with single-injection peripheral nerve block: a systematic review and meta-analysis of randomized controlled trials. Reg Anesth Pain Med 2012;37:583-94.

[26] DerSimonian R, Laird N. Meta-analysis in clinical trials. Control Clin Trials 1986;7:177-88.

[27] Maes S, Laubach M, Poelaert J. Randomised controlled trial of spinal anaesthesia with bupivacaine or 2-chloroprocaine during caesarean section. Acta Anaesthesiol
Scand 2016;60:642-9.

[28] Lacasse MA, Roy JD, Forget J, Vandenbroucke F, Seal RF, Beaulieu D, et al. Comparison of bupivacaine and 2-chloroprocaine for spinal anesthesia for outpatient surgery: a double-blind randomized trial. Can J Anaesth 2011;58:384-91.

[29] Teunkens A, Vermeulen K, Van Gerven E, Fieuws S, Van de Velde M, Rex S. Comparison of 2-Chloroprocaine, bupivacaine, and lidocaine for spinal anesthesia in patients undergoing knee arthroscopy in an outpatient setting: a double-blind randomized controlled trial. Reg Anesth Pain Med 2016;41:576-83.

[30] Yoos JR, Kopacz DJ. Spinal 2-chloroprocaine for surgery: an initial 10-month experience. Anesth Analg 2005;100:553-8.

[31] Forster JG. Short-acting spinal anesthesia in the ambulatory setting. Curr Opin Anaesthesiol 2014;27:597-604.

[32] Liu SS, Strodtbeck WM, Richman JM, Wu CL. A comparison of regional versus general anesthesia for ambulatory anesthesia: a meta-analysis of randomized controlled trials. Anesth Analg 2005;101:1634-42.

[33] Fanelli A, Ghisi D, Allegri M. Is spinal anaesthesia a suitable technique for ultrashort outpatient procedures? Acta Biomed 2013;84:76-80.

[34] Forster JG, Rosenberg PH, Harilainen A, Sandelin J, Pitkanen MT. Chloroprocaine $40 \mathrm{mg}$ produces shorter spinal block than articaine $40 \mathrm{mg}$ in day-case knee arthroscopy patients. Acta Anaesthesiol Scand 2013;57:911-9.

[35] Breebaart MB, Teune A, Sermeus LA, Vercauteren MP. Intrathecal chloroprocaine vs. lidocaine in day-case surgery: recovery, discharge and effect of pre-hydration on micturition. Acta Anaesthesiol Scand 2014;58:206-13.

[36] Forster JG, Kallio H, Rosenberg PH, Harilainen A, Sandelin J, Pitkanen MT. Chloroprocaine vs. articaine as spinal anaesthetics for day-case knee arthroscopy. Acta Anaesthesiol Scand 2011;55:273-81.

[37] Valanne JV, Korhonen AM, Jokela RM, Ravaska P, Korttila KK. Selective spinal anesthesia: a comparison of hyperbaric bupivacaine $4 \mathrm{mg}$ versus $6 \mathrm{mg}$ for outpatient knee arthroscopy. Anesth Analg 2001;93:1377-9.

[38] Casati A, Danelli G, Berti M, Fioro A, Fanelli A, Benassi C, et al. Intrathecal 2chloroprocaine for lower limb outpatient surgery: a prospective, randomized, double-blind, clinical evaluation. Anesth Analg 2006;103:234-8.

[39] Casati A, Fanelli G, Danelli G, Berti M, Ghisi D, Brivio M, et al. Spinal anesthesia with lidocaine or preservative-free 2-chlorprocaine for outpatient knee arthroscopy: a prospective, randomized, double-blind comparison. Anesth Analg 2007;104:959-64.

[40] Sell A, Tein T, Pitkanen M. Spinal 2-chloroprocaine: effective dose for ambulatory surgery. Acta Anaesthesiol Scand 2008;52:695-9.

[41] Kamphuis ET, Ionescu TI, Kuipers PW, de Gier J, van Venrooij GE, Boon TA. Recovery of storage and emptying functions of the urinary bladder after spinal anesthesia with lidocaine and with bupivacaine in men. Anesthesiology 1998;88:310-6.

[42] Pavlin DJ, Pavlin EG, Gunn HC, Taraday JK, Koerschgen ME. Voiding in patients managed with or without ultrasound monitoring of bladder volume after outpatient surgery. Anesth Analg 1999;89:90-7.

[43] Choi S, Mahon P, Awad IT. Neuraxial anesthesia and bladder dysfunction in the perioperative period: a systematic review. Can J Anaesth 2012;59:681-703.

[44] Mulroy MF, Alley EA. Management of bladder volumes when using neuraxial anesthesia. Int Anesthesiol Clin 2012;50:101-10.

[45] Voelckel WG, Kirchmair L, Rehder P, Garoscio I, Krappinger D, Luger TJ. Unilateral anesthesia does not affect the incidence of urinary retention after low-dose spinal anesthesia for knee surgery. Anesth Analg 2009;109:986-7.

[46] Nishikawa K, Yoshida S, Shimodate Y, Igarashi M, Namiki A. A comparison of spinal anesthesia with small-dose lidocaine and general anesthesia with fentanyl and propofol for ambulatory prostate biopsy procedures in elderly patients. J Clin Anesth 2007;19:25-9.

[47] Mulroy MF, Salinas FV, Larkin KL, Polissar NL. Ambulatory surgery patients may be discharged before voiding after short-acting spinal and epidural anesthesia. Anesthesiology 2002;97:315-9.

[48] Gebhardt V, Herold A, Weiss C, Samakas A, Schmittner MD. Dosage finding for lowdose spinal anaesthesia using hyperbaric prilocaine in patients undergoing perianal outpatient surgery. Acta Anaesthesiol Scand 2013:57:249-56.

[49] Manassero A, Bossolasco M, Ugues S, Bailo C, Liarou C, Coletta G. Comparison of unilateral and bilateral spinal anesthesia with $2 \%$ hyperbaric prilocaine in day-case inguinal herniorrhaphy: a randomized controlled trial. Minerva Anestesiol 2014;80:685-91. 